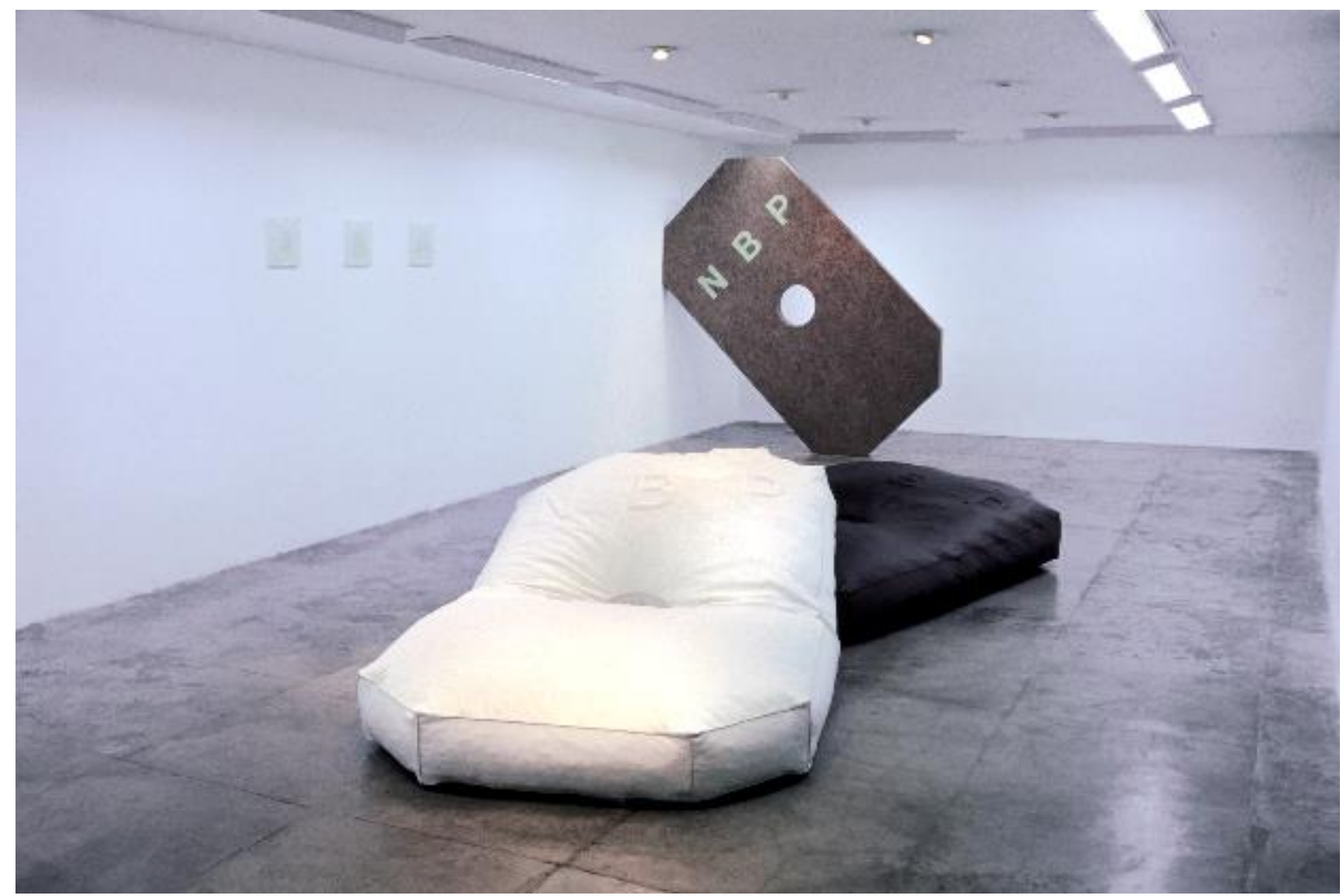

Ricardo Basbaum

NBP - Novas bases para a personalidade, 1993

Napa, espuma, fórmica, serigrafia

Vista geral exposição de mesmo título na Galeria Sergio Porto, Rio de Janeiro

foto Vicente de Mello

\title{
Repersonalização, enfrentamento e reversibilidade ${ }^{1}$
}

Maria Moreira ${ }^{2}$

1 Um intervalo de cinco anos separa os dois títulos aqui apresentados sobre a obra de Ricardo Basbaum: Rigor / Ressonância, escrito em 1992, revisto em 1997, intenta analisar as estratégias de funcionamento interno do projeto NBP Novas bases para a personalidade, relacionando-as aos conceitos específicos de Repersonalização e Variedade, tidos como constituintes de uma certa brasilidade a ser lida, não como relação forma/conteúdo mas, como função de uma singularidade de percepção e comportamento, disseminada na cultura; Arte como Enfrentamento: Diário de Campo, escrito em 1997, é uma pequena avaliação do funcionamento da interface externa do projeto NBP, mapeando a flexibilidade das intuições sobre administração de conflito, visíveis na relação obra-contexto. Os dois títulos foram reunidos e publicados na Revista item.5, Rio de Janeiro: Espaço Agora/Capacete, 2002.

2 Maria Moreira (1954) investiga formas extensivas de espaços de partilha, misturando materialidades e as circunstâncias do entorno. Vive e trabalha no Rio. Graduou em Arquitetura, USU/ RJ, tem mestrado em Comunicação ECO/ UFRJ, mestrado em Artes, Goldsmiths, University of London, UK e doutorado, Central Saint Martins/ UAL/ UK. Expôs solo e em coletivas no Rio, SP, BH, Londres, Paris, Innsbruck, NY. Atualmente é professora adjunta DE do Instituto de Artes da UERJ. 


\section{Rigor / Ressonância}

As significâncias, segundo Barthes ${ }^{3}$, ligadas às artes como a ordem dos signos está ligada à língua, ocorrem quando um núcleo semântico é envolvido por "um campo de expansão infinita em que o sentido transborda, irradia, sem perder sua impressão (a capacidade de imprimir-se)". No seu induz ao uso não fixado da matéria e dos objetos, como vemos demostrado na sua fase atual, desenvolvida sob o fio condutor NBP - Novas bases para a personalidade.

NBP é como uma espécie de salvo conduto para a utilização de qualquer meio de expressão. O uso da sigla, sobreposta a superfícies as mais distintas ou constituindo o trabalho em si, como forma inserida em objetos, é uma prática de apropriação da variedade do mundo. Uma voracidade, no entanto, discreta e imune ao cinismo ou à indiferença.

Cuidadosamente aderido, mas não fixado aos seus objetos, Basbaum nos propõe a solidariedade frente ao vário, anulando na variedade seu caráter de diversidade, que seria a variedade contraposta a si mesma. Os objetos da fase NBP são como estações autônomas, jogadas numa relação nãohierárquica de totalidades, à espreita da fluidez de percurso do observador. Indicam uma postura que fala, nos parece, de uma certa brasilidade, aflorando como uma injunção cultural, uma força independente das intenções conscientes do artista.

Novas bases para a personalidade é uma fórmula que apreende um dado fundamental para o que chamamos aqui de "uma certa brasilidade" — a experiência de repersonalização. Apesar da patente semelhança entre os nomes, o fato ocorreu ao modo de um processo não-consciente para Basbaum, aí atuando, à própria revelia, como um criador atravessado por determinantes da comunidade geral onde está inserido.

No Brasil a repersonalização, como dado do imaginário, é um fato de cultura decorrente da diáspora africana no país, sendo uma das respostas do negro frente ao branco, na situação de quase extermínio criada pela escravidão. A repersonalização é um estratagema de convivialidade. Desenvolvida, inicialmente, como "estratégia escrava de sobrevivência" ${ }^{4}$, dissemina-se, após o fim da escravatura, como "estratégia subalterna de subsistência", exercida, na busca de inserção social, pelo novo grupo de excluídos gerado no processo de libertação.

3 BARTHES, Roland. O óbvio e o obtuso: ensaios críticos III. Rio de Janeiro: Nova Fronteira, 1990, p.284.

4 MOURA, Roberto. Tia Ciata e a Pequena África no Rio de Janeiro. Rio de Janeiro: Funarte, 1983, p.110. 
Baseia-se a repersonalização na atitude cultural de instaurar zonas de contágio, onde ocorre a mistura dos códigos, ao redor de núcleos de segredo, onde a diferença de uma cultura frente a outra se realimenta. Preservando núcleos de segredo, ligados à iniciação nos cultos religiosos, a cultura afro-brasileira se reafirmou e fortaleceu sua identidade. Nas áreas de contágio - rodas de samba, por exemplo - ela se expandiu, comunicou, assimilou novos dados e, por uma espécie de sedução combativa, legitimou-se frente ao outro. Belo trabalho no domínio das significâncias. O uso atento dos mecanismos de troca cultural, permitiu às formas de expressão características do grupo, como a música, a comida e a gestualidade, recriarem-se para encontrar ressonância na comunidade geral, e, por adesão, se constituírem em parcela significativa dos fatos típicos da nacionalidade.

O padrão de comportamento da repersonalização se estabeleceu a partir da singularidade dos esquemas lógicos da comunidade afro-brasileira, articulados, inicialmente, na situação de solidariedade forçada entre os dignitários de etnias hostis, amontoados, cada qual com seu saber sagrado, nos porões dos navios negreiros.

Segundo Bastide ${ }^{5}$, o pensamento afro-brasileiro é pautado por dois princípios: o princípio de participação, pelo qual todas as coisas existentes estão ordenadas por filiações a forças arbitradas - os orixás; e o princípio de cisão que, regulando o anterior, impede a passagem de itens de um rol de filiação para outro. Os dois princípios guiam a percepção no reconhecimento de "semelhanças por eficiência", quando entidades, mesmo pertencendo a explicações de mundo diversas, atuam regidas por forças arbitradas análogas.

A capacidade de detectar paridade entre os deuses distintos das diferentes etnias africanas, foi a ferramenta simbólica que permitiu acomodar hostilidades entre tribos inimigas, no trabalho de solidariedade necessário ao enfrentamento de um mesmo destino adverso - a escravidão. Como matriz de pensamento, o reconhecimento de "semelhanças por eficiência", foi a base da leitura que a comunidade afro-brasileira fez das figuras sagradas da cristandade, no seu esforço de encontrar um território comum de trocas simbólicas, para a negociação da sobrevivência.

Contrariando a ideia aceita da existência de sincretismo na cultura brasileira, Bastide afirma que, por conta do princípio de cisão, o reconhecimento de uma relação regida pelo princípio de participação, por exemplo entre Iemanjá e Nossa Senhora, não leva à conversão, à eliminação, ou à assimilação de um item pelo outro. Simplesmente, cada qual permanece operante na especificidade de seu esquema explicativo de mundo, e é o sujeito da percepção dessa analogia

5 BASTIDE, Roger. Sociologia. Org. Maria Isaura Pereira Queiroz. São Paulo: Ática, 1983, p.208. 
que deverá encontrar uma certa fluidez singular, para circular entre os blocos lógicos de cada esquema, acionando o real a partir de uma lógica ou de outra, de acordo com as circunstâncias.

Podemos dizer que a fluidez de percurso é a essência do processo de repersonalização. O sujeito da fluidez não alimenta decepções ao experienciar que narrativas fundadoras distintas são capazes de operar o real enquanto eficiências paralelas. Por consequência, tem facilidade em assumir, tranquilamente, a variedade inerente ao mundo, domando-a pela sutileza das contextualizacões.

É, principalmente, em torno deste tipo específico de consciência da variedade, como multiplicidade sem contraposição, multiplicidades simultâneas e apostas, às vezes complementares, que se dá o contato entre o modelo de comportamento cultural e a formalização da fase atual de Ricardo Basbaum. Mas antes de dar prosseguimento, deixemos claro que a adequação de NBP a um dado da cultura geral do país, a repersonalização, ocorre sem um envolvimento direto nas questões da nacionalidade, sem manifestos ou subserviências a iconografias típicas (vide PS.).

O projeto NBP surge como fruto de um longo esforço de compreensão, ligado a questões bem internas do fazer artístico, e afinado com a cena internacional. A busca da imagem — nos primeiros anos de pintura, início da década de 80; o questionamento do suporte — nas pinturas recortadas; a passagem para a tridimensionalidade - nas pinturas instaladas; o uso das mídias — nas performances, no uso do logotipo do olho e nos cartazes de rua; o trabalho coletivo com a Dupla Especializada e o Grupo Seis Mãos e o trabalho teórico, em textos publicados e cursos de leitura em artes plásticas.

Durante muito tempo Basbaum desnorteou a plateia com suas súbitas mudanças de linha, com trabalhos que foram ficando ora herméticos ora francamente inconfortáveis, como a longa série de micro-instalações que atravessou toda a segunda metade da década de 80 , ocorrendo entremeada a outros trabalhos. Olhando em retrospectiva, é sem dúvida na experiência destas fases, às vezes acontecendo em sucessão, às vezes em paralelo, com trabalhos erguidos numa posição limítrofe entre pintura, objeto, instalação e performance, que podemos localizar a gênese do que foi apontado como o fator determinante para NBP: a atitude frente ao conceito de variedade.

A variedade é um dos modos do excesso. Pode-se lidar com o excesso a partir de um vetor exclusivo ou inclusivo. Nas artes visuais, o vetor exclusivo demarca limites em torno das zonas de linguagem, concedendo uma certa inteligibilidade à cena artística, ordenando-a por escolha de vocabulário. Contra o conforto desta inteligibilidade age o vetor inclusivo, afirmando um 
pluralismo extremo e uma complexidade de coexistência para os diversos meios de expressão, numa manobra ultra-contemporânea de captura dos "traços erráticos" descontínuos, que estruturam a imagem como significância.

Falando sobre significância, Barthes indica dois níveis de apreensão do sentido: o sentido óbvio, "da evidência fechada, presa em um sistema completo de destinação", constituído pelo que "se apresenta naturalmente ao espírito", e o sentido obtuso, velado, cuja extensão está "fora da cultura, do saber, da informação". O segundo, sendo "indiferente às categorias morais ou estéticas (o trivial, o fútil, o postiço e o pastiche)", enquadra-se na categoria do carnaval, configurando-se numa dobra acolhedora das ressonâncias, do impreciso, do excesso, capaz de confundir não apenas o conteúdo, mas a totalidade das relações sígnicas enquanto referência.

A referência, segundo Marshall Sahlins ${ }^{6}$, é uma relação duplamente arbitrária de "segmentação relativa e representação seletiva", e coloca o sistema de sentido em situação de "risco empírico" ao lidar com a variedade contida em outros sistemas de intensidade, como o "sujeito inteligente" envolvido no uso motivado dos signos para seus projetos pessoais, e o "mundo intransigente" capaz de contradizer, pela multiplicidade das coisas, o sistema sígnico erguido para o descrever.

Face ao pragmatismo e ao acaso de outros sistemas, a referência apresenta uma tendência a restringir e "fixar a cadeia flutuante dos significados, de modo a combater o terror dos signos incertos". O embate, no cotidiano, gera uma situação de favorecimento para a atitude de controle do texto que, investido da "responsabilidade pelo uso da mensagem", questiona a imagem, basicamente um signo polissêmico, plasmando sobre tudo a pergunta "o que é isto?"

Pelo menos em três instantes na história das artes visuais deste século [XX], essa situação de controle na relação texto/imagem foi usada como material de trabalho: o cachimbo/não cachimbo de Magritte; o telegrama/retrato de Rauschenberg; o copo d'água/pé de carvalho de Craig-Martin. Os três trabalhos apresentavam uma situação de contra-ilustração comentada. Um objeto era positivado como imagem soberana pela negação do seu sentido óbvio e mergulho na "ebulição das conjecturas" do sentido obtuso. Por uma contra-demonstração arbitrária ("isto não é um cachimbo"), a situação de controle das ressonâncias, na relação texto/imagem, era desestabilizada, ao ser radicalmente levada ao seu ponto extremo de inteligibilidade por consenso.

6 SAHLINS, Marshall. Ilhas de História. Rio de Janeiro: Zahar, 1990, p.218. 
NBP vai tratar a mesma questão de uma forma um tanto diversa. Ciente da irredutibilidade de um sistema ao outro, Basbaum abandona qualquer intenção de comentário da relação texto/imagem e opta por sobrepor as unidades de discurso, instaurando-as a partir de um tempo unificado de criação. Nos melhores exemplares de NBP, nunca a imagem ilustra o texto (a sigla), ou o texto legenda a imagem. Não existe precedência ou referência. A situação de controle é implodida porque, além da simultaneidade, nenhuma relação óbvia é proposta.

É no terreno do obtuso, das ressonâncias, que uma conexão não-hierárquica se estabelece: novas bases da personalidade/multiplicidade de meios. Estando fora do território da representação, e portanto, fora do alcance das leis armazenadas na cultura para reger a condição de símbolo, a pura apresentação de dois róis de variedades demonstra o sistema icônico da imagem como uma competência paralela ao sistema indicial da língua. Ambos irão, por justaposição, constituir o trabalho numa estrutura de realimentação contínua, um jogo de contaminações sem ascendências. Com NBP, Basbaum criou um projeto de longa duração, na linha dos números de Opalka, com a diferença capital de ser amplamente permeável à variedade, de um modo peculiarmente brasileiro, e à experimentação, de um modo bem contemporâneo. Um projeto exposto a todos os contágios, sem o risco de, com o passar do tempo, perder o seu eixo, pois o eixo é composto, justamente, pela articulação entre duas possibilidades de fluidez na mudança: o sentido não explicitado no texto-sigla NBP, e a multiplicidade sem limites dos meios de expressão, utilizáveis pela imagem circunstancial. 


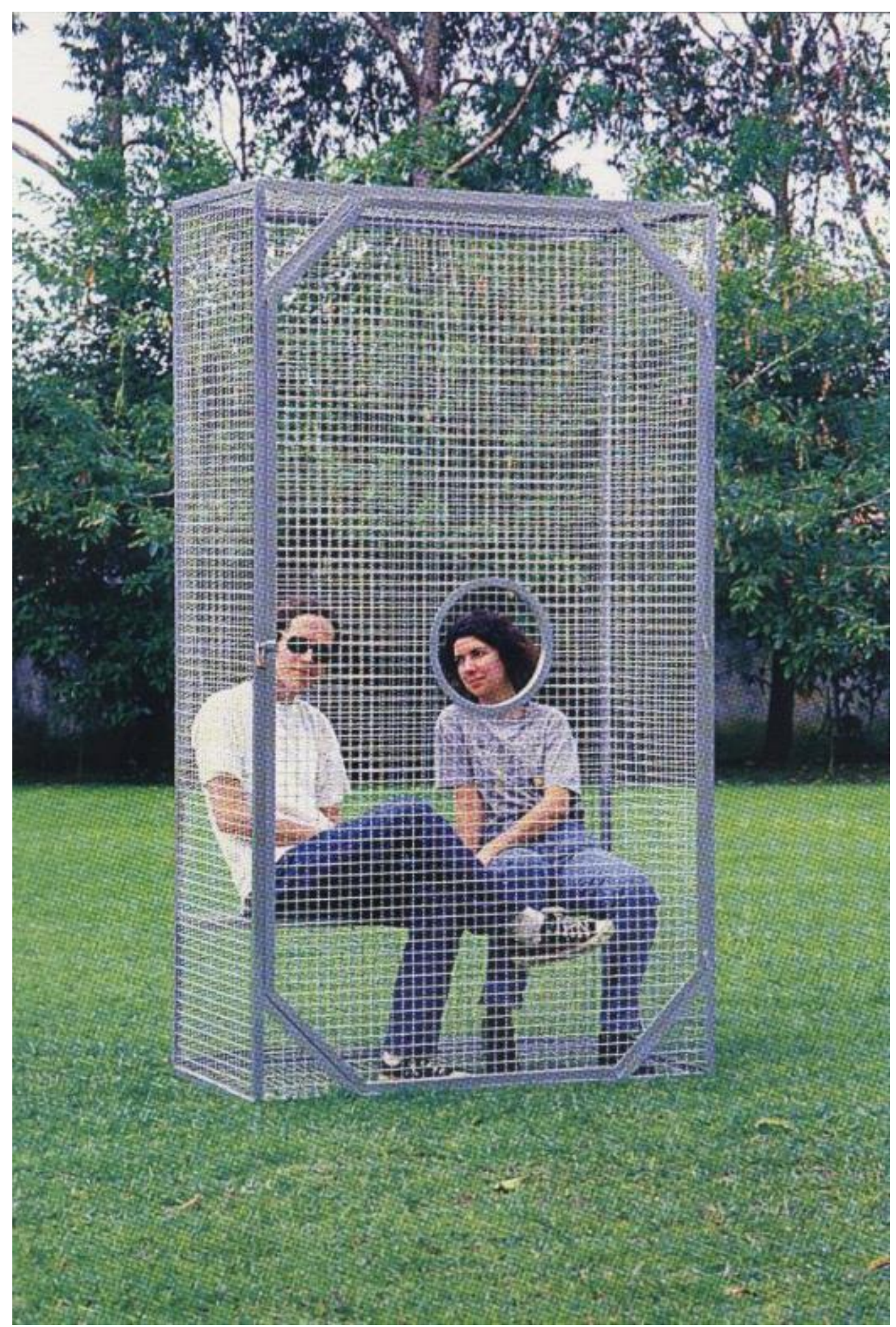

Ricardo Basbaum

NBP - Novas bases para a personalidade, $1993^{7}$

Ferro, grade de ferro, cadeado.

228 x 129 x $80 \mathrm{~cm}$ - coleção particular

7 Nas imagens, os artistas João Modé e Marcia Ramos. 
foto Vicente de Mello

\section{PS. Repersonalização: antropofagias, tropicálias, hibridismos, lateralidades...}

Paulo Venâncio, num texto ${ }^{8}$ sobre Cildo Meireles e Tunga, afirma que a lateralidade, enquanto um olhar oblíquo, não polarizado, é a posição estrutural da percepção capaz de articular "a tradição da história da arte moderna e um determinado contexto social". Primeiro negando a esta "posição estrutural" valor de identidade e depois, duas frases adiante, sugerindo que nossa identidade "é esse esforço de introjeção, de obsessiva vivência e reflexão das matrizes culturais", Paulo Venâncio, apesar da leve oscilação, explicita, lucidamente, a questão central que, ao menos há 70 anos, aflora no pensamento das visualidades brasileiras, quando se trata de definir uma identidade nacional no setor.

A vantagem do termo lateralidade em relação à Antropofagia, Tropicalismo ou Hibridismo, que participam, com maior ou menor acerto, de uma mesma intuição conceitual, reside no fato de ser a lateralidade o termo mais isento de sugestões formais. Vinculando uma indicação de movimento, o termo carrega a marca da "fluidez de percurso entre blocos lógicos" de que falávamos ao apresentar a experiência da repersonalização como um dado fundador do imaginário nacional. Enfatizando a ação do sujeito que circula e não os objetos entre os quais ele circula, a lateralidade aponta para a não-aderência às iconografias experimentadas, ressaltando a atitude básica da condição de fluidez perceptiva.

A clareza conceitual de um termo como lateralidade, se fazendo possível no presente, talvez seja um sintoma da universalização de certos procedimentos nas sociedades de informação, possuidoras de um potencial de acesso amplo a imagens e discursos. O que foi constitucional para comunidades transculturais como a nossa - a necessidade de articulação entre a diversidade de metarrelatos fundadores, enfrentada pelo índio, pelo negro e pelo europeu em terras brasileiras tornou-se agora o circunstancial cotidiano para parcelas cada vez maiores da comunidade internacional, lidando com um fluxo continuo de informações. Aguçadas, as sensibilidades contemporâneas descobrem o valor pragmático das lateralidades não-polarizadas.

Um novo jogo de percepção e ação para o mundo, para nós, um velho conhecido, a lateralidade é talvez um outro nome para a experiência da repersonalização. Graças ao citado "esforço de introjeção, obsessiva vivência e reflexão das matrizes culturais", há muito tempo gerou-se na

8 VENÂNCIO FILHO, Paulo. Situações limites, in Tunga's Lezarts, Cildo Meireles' Through. Bélgica: Kunststichting-Kanaal Art Fundation, 1989, pp.26-27. 
cultura brasileira um padrão comunicacional de largo espectro, capaz de acolher os discursos mais díspares. Purgado de alguns vícios eventuais de funcionamento - a indiferença, a irresponsabilidade, a negligência-, o padrão possui a digna sofisticação de um jogo lógico, plenamente aberto às circunstâncias. Sendo propício à fragilidade humana nas situações de risco, é adequado ao momento presente do cenário internacional, tanto quanto foi adequado, na cena afro-brasileira, à situação de quase extermínio, criada pela escravidão. Eis a razão pela qual um artista trabalhando com questões contemporâneas de um vocabulário internacional, possa estar tão impregnado desta tal "brasilidade".

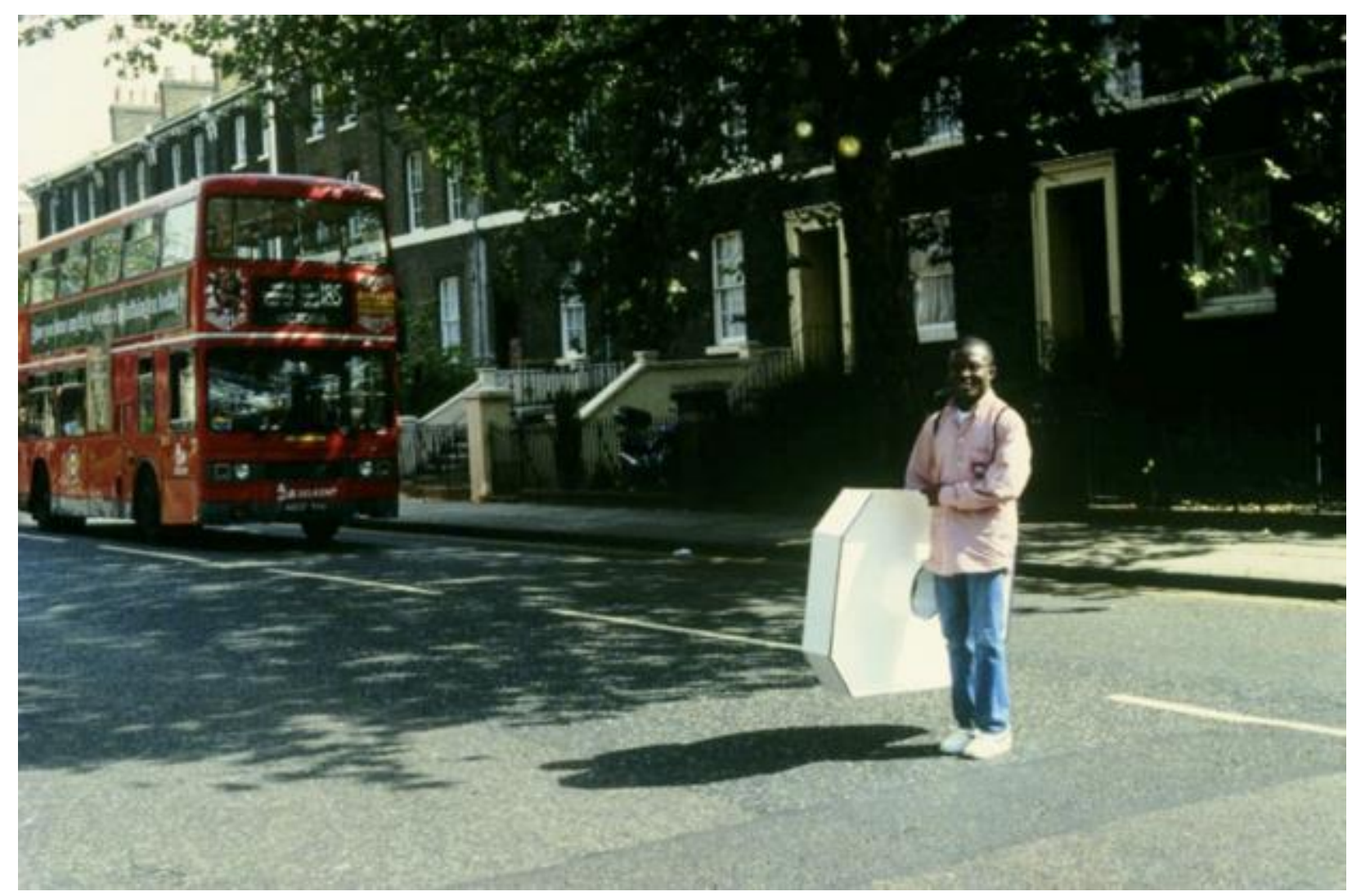

Ricardo Basbaum

Você gostaria de participar de uma experiência artística? (trabalho em progresso desde 1994) objeto de ferro pintado, experiência $125 \times 80 \times 18 \mathrm{~cm}$ participação Hogan Antia, Londres, 1994

foto cortesia participante; projeto Você gostaria de participar de uma experiência artística?

\section{Arte como enfrentamento: diário de campo}

Desde 1989, Ricardo Basbaum vem desenvolvendo uma forma não-dicotômica de inserir a dualidade Texto/Imagem no seu trabalho. A opção está claramente indicada no projeto NBP tanto 
pela escolha de tratar o texto como sigla - conjunto de letras percebido como marca, forma fechada; quanto pela escolha de tratar a imagem como emblema - forma contaminada por um funcionamento referencial, próprio dos nomes institucionais.

De 1993 em diante, o movimento de colapso da dicotomia Texto/Imagem se completa com a inclusão de diagramas, como unidade vocabular de destaque no projeto NBP. Nos diagramas, linhas de desenho atuam com a função gramatical de articular, num discurso de ação, os elementos da narrativa, como manchas, texturas e palavras que, dotadas de um procedimento de figura, agem como âncoras transitórias, na composição do olhar sobre a imagem final.

Os diagramas NBP são diagramas de enfrentamento. Como tal, mais que superfícies de registro, são superfícies de acumulação, sobreposições de percursos em série, revelando as forças de oscilação envolvidas na ambiguidade dos jogos de proximidade. Demarcam situações em processo, onde possibilidades futuras são passíveis de serem alteradas pelo próprio ato de demarcálas. São diagramas em forma de circuito de risco, diagramas em aberto. Indicam não as estruturas que interligam os elementos, mas as situações de enfrentamento ao pressionar as estruturas.

Na exposição Novas bases para a personalidade (Galeria do Ibeu, Rio de Janeiro, agosto de 1993), os diagramas falavam sobre os enfrentamentos decorrentes de situações de captura eu-você, situações de sedução e perda, iconizadas nos objetos que compunham a instalação: um bancogaiola para duas pessoas, feito em tela de aço e estrutura de ferro; um conjunto de almofadas em forma emblemática e tapete. Em oferta uma situação de conforto — sentar, deitar —, ao preço da submissão mútua ao olhar do outro. Por meio de uma manobra de reversão contínua dos lugaresprocedimentos, adequados ao sujeito que observa e ao objeto observado, estabelecia-se a visibilidade como risco e moeda de troca nos jogos de proximidade.

Em 1997, na exposição NBP: Identidade/Arquitetura (Espaço Aberto UFF, Niterói), o enfrentamento se dá não mais entre indivíduos (eu-você), mas entre o território de poder do indivíduo e o território de poder das instituições. Talvez por uma questão de desigualdade entre os territórios em conflito, a manobra acionada foi a de resistência na invisibilidade.

No hall de entrada da universidade, Basbaum duplicou os objetos: balcão, quadro de avisos e escaninho. E o fez de forma tão mimética que, numa primeira visita, não percebi a obra em sua totalidade, só o escaninho com os diagramas. Retornei num domingo e observei a instalação através do vidro, pelo lado de fora da porta de entrada fechada. À distância, o texto do quadro de 
avisos criado pelo artista, cujo conteúdo difere do institucional, não podia ser lido, apenas a tipografia podia ser percebida, sendo mais delgada e elegante que a emulada.

O mimetismo é uma estratégia de combate que se utiliza de invisibilidades contextuais, onde o corpo se torna função das ameaças do meio, respondendo com um impulso de cópia, silêncio e imobilidade. Mas este impulso de apagamento, na natureza, é alimentado desde o interior por uma vontade de sobrevivência e afirmação da continuidade da vida em seus limites. Alegria secreta, participando da invisibilidade como o ruído futuro de um segredo explosivo.

Talvez esta seja a linha de fuga indicada pela elegância da tipografia do quadro de avisos duplicado: uma elegância natural sendo apresentada como a alegria de se saber sutilmente visível, mesmo em situações limites de apagamento. É surpreendente encontrar, num indício tão mínimo do campo visual, um núcleo de resistência. É revelador que se localize num detalhe tipográfico. Esta é uma montagem inquietante na sua sobriedade, sombria mesmo. Ao introjetar os mecanismos de invisibilidade como estratégia de combate com setores do real superpotente, no caso a Universidade, o artista visual se transmuta no Homem Invisível, sem acesso direto à um corpo ativo que se rebele, só linguagem, sempre a ser purgada do condicionamento das chaves de leitura. A questão se coloca: qual a relação entre artifícios de presença do corpo e a obra como suporte de sentido ampliado? Entendemos que a retirada do corpo do artista, se dando tanto pela negação das marcas específicas de feitura (uso de objetos industrializados), quanto, no caso, pela recusa da criação de uma forma intransferível (adoção de objetos duplicados), visa criar um vácuo a ser preenchido pelo corpo do outro, convocado, por integração ou resistência, a tornar-se o agente da extensão necessária dos limites de articulação da linguagem.

O procedimento indicado é investigado na série, iniciada por Basbaum em 1994 e ainda em curso, Você gostaria de participar de uma experiencia artística? Através do convite, um objeto de feitura industrial, com uma forma específica, mas passível de ser duplicado e desrespeitado em sua relação canônica com o espaço circundante - pode ser colocado de qualquer jeito em qualquer posição —, é oferecido ao uso e desuso de quem se disponha a participar da experiência. No atual estágio do projeto as possibilidades de interação parecem ser balizadas por duas características principais:

Reversibilidade - função do uso e desuso oferecidos aos participantes. Se a manipulação respeitar os limites de integridade do objeto, ele sempre poderá retornar à sua condição de objeto de galeria, a ser exposto acompanhado do registro de seus encontros no mundo; 
Banalização - demonstrada, com ênfase, no trabalho resposta que apropriou-se, não do objeto mas, da sua forma emblemática ${ }^{9}$, expondo-a aos riscos de todo um rol de versões delirantes, com perda de proporções e alterações de material. Trata-se de uma manobra de inclusão, onde o simulacro não chega a se instaurar, como série que anula a origem, pois toda a ação é uma interação de humor. Uma paródia sobre o objeto de arte como referencial de contaminação, revestindo o mundo qual um mistério aceito, que paradoxalmente confere ao sujeito, em enfrentamento com a variedade da existência, uma chave de entendimento revelado como experiência pessoal e intransferível.

No campo demarcado por estas duas variáveis, risco e defesa são como o veneno e o antídoto vindo da mesma matéria, pois a reversibilidade é uma das características de certo mimetismo, e o mimetismo é o impulso inicial dos processos de banalização.

Retornemos ao enfrentamento inicial eu/você onde começou a ciranda de riscos: repersonalização/resistência; visibilidade/invisibilidade; mimetismo/banalização. Os enfrentamentos subseqüentes — indivíduo/instituição, objeto/usuário —, são apenas transposições ampliadas do mesmo conflito. O grande achado para liberar o campo de embate do tingimento em cores sombrias (ou sóbrias), é, me parece, a entrada em cena do conceito de reversibilidade.

A compreensão da reversibilidade como um dado do real, reinstaura uma alegria potente face aos riscos dos jogos de proximidade, os jogos experimentais de constituição do ser, que passam a ser vividos como conjuntos de regras contextuais, leis sem apegos, simultâneas e negociáveis. A reversibilidade, como virtude da passagem, é uma experiência de saber condicionada à fluidez de interação, sendo modelar para o acionamento das narrativas de transmutação dos possíveis.

Sobre as relações da reversibilidade com a sociedade geral, podemos dizer que a reversibilidade é um dado de acesso direto/difuso em sociedades que possuam religiões lidando com o fenômeno da incorporação - a experiência paradigmática da reversibilidade entre condições do ser. Mesmo quando não reconhecidas como a religião oficial do país, como o taoísmo na China ou o candomblé no Brasil, a forte presença na cultura lhes permite plasmar figuras de saber no inconsciente antropológico da nação. Por este canal, nos parece, a reversibilidade age como o fato cultural que torna viável, mesmo sob fortes restrições, a absorção pela comunidade de fatos políticos difíceis,

9 A experiência está registrada no vídeo Um Registro de constatação de arte no projeto NBP de Ricardo Basbaum de Pedro de Vasconcellos e Wagner Vasconcelos (SIM ou ZERO), Enseada das Garças, ES, 1994. 
como Um país, dois sistemas (China), ou a troca constante do padrão de moeda (Brasil) ${ }^{10}$. Como se vê, trata-se de um mecanismo poderoso e o seu uso exercita sérias demandas de responsabilidade.

Incluindo a reversibilidade em seu repertório, Basbaum equaciona conflito e alegria (a prova dos nove) de uma forma sutil, não óbvia, quase secreta. A retirada do corpo-presença do artista, se dando em prol de um instante de corpo-reflexão, corpo-receptáculo-do-outro, atrai no seu vácuo potenciais do futuro para uma interação no presente, revertendo as regras entre produção e recepção do fato artístico e abrindo o jogo da criação ao indeterminado.

\footnotetext{
10 Nos últimos trinta anos foram realizadas no país sete reformas monetárias. O nome da moeda ziguezagueou entre Cruzeiro, como era antes de 1964, ao se iniciar a ditadura, Cruzeiro Novo (1967), Cruzeiro outra vez(1970), Cruzado (1986), Cruzado Novo (1989), Cruzeiro mais uma vez (1990), Cruzeiro Real (1993) e, finalmente, Real (1994), nome de uma antiga unidade monetária, tanto de Portugal quanto do Brasil. A ilustração das cédulas neste período de trinta anos seguiu uma linha evolutiva peculiar. Trazendo sempre no verso imagens complementares ao tema escolhido, começa com os vultos históricos da tradição, incorpora os expoentes da cultura como músicos, poetas, pintores, escritores, cientistas, passa aos tipos regionais — o gaúcho e a baiana-, e se detém neste segundo lançamento. Chega o Real e ocorre uma mudança. As cédulas de diferentes valores passam a manter fixas, de um lado, a efígie da República, e, do outro, estampam exemplares da fauna nacional. A série começa, na nota de um Real, com a imagem do colibri alimentando seus filhotes, imagem já utilizada anteriormente na nota de cem mil cruzeiros, como complementar a figura de Augusto Ruschi. Do mesmo modo, a efígie da República já tinha sido usada na nota de duzentos cruzados novos (1989) e, logo depois, na de duzentos cruzeiros (1990). Não deixa de ser interessante esse movimento duplo, que, no nome, abandona as estrelas (o Cruzeiro) e retorna ao Real, e, na imagem, abandona paulatinamente o culto à personalidade e busca, de um lado, a natureza animal e, do outro, a fixação de uma ideia abstrata, referente a um compromisso de administração do coletivo (a efígie da República).
} 